\title{
Avoiding acidic region streaking in two-dimensional gel electrophoresis: Case study with two bacterial whole cell protein extracts
}

\author{
Arnab Roy ${ }^{l}$, Umesh VARshney ${ }^{2}$ and Debnath PaL ${ }^{1, *}$ \\ ${ }^{1}$ Bioinformatics Centre, Supercomputer Education and Research Centre and ${ }^{2}$ Department of \\ Microbiology and Cell Biology, Indian Institute of Science, Bangalore 560 012, India \\ *Corresponding author (Fax, +918023602648; Email,dpal@serc.iisc.in)
}

\begin{abstract}
Acidic region streaking (ARS) is one of the lacunae in two-dimensional gel electrophoresis (2DE) of bacterial proteome. This streaking is primarily caused by nucleic acid $(\mathrm{NuA})$ contamination and poses major problem in the downstream processes like image analysis and protein identification. Although cleanup and nuclease digestion are practiced as remedial options, these strategies may incur loss in protein recovery and perform incomplete removal of NuA. As a result, ARS has remained a common observation across publications, including the recent ones. In this work, we demonstrate how ultrasound wave can be used to shear NuA in plain ice-cooled water, facilitating the elimination of ARS in the 2DE gels without the need for any additional sample cleanup tasks. In combination with a suitable buffer recipe, IEF program and frequent paper-wick changing approach, we are able to reproducibly demonstrate the production of clean 2DE gels with improved protein recovery and negligible or no ARS. We illustrate our procedure using whole cell protein extracts from two diverse organisms, Escherichia coli and Mycobacterium smegmatis. Our designed protocols are straightforward and expected to provide good 2DE gels without ARS, with comparable times and significantly lower cost.
\end{abstract}

[Roy A Varshney U and Pal D 2014 Avoiding acidic region streaking in two-dimensional gel electrophoresis: Case study with two bacterial whole cell protein extracts. J. Biosci. 39 631-642] DOI 10.1007/s12038-014-9453-9

\section{Introduction}

Since O'Farrell's paper in 1975 (O'Farrell 1975), twodimensional gel electrophoresis (2DE) has become a useful tool in the analysis of complex protein mixtures, especially after the popularization of mass-spectrometry-based methods to identify proteins (Henzel et al. 1993; James et al. 1993; Pappin et al. 1993; Rabilloud et al. 2010; Yates et al. 1993). Its capacity to resolve thousands of proteins in a single gel and to detect post- and co- translational modifications (Lopez 2007; Rabilloud 2002) has made 2DE a popular instrument in modern proteomics (Butt et al. 2012; Hong et al. 2013; Pal et al. 2013; Rajani et al. 2012; Sun et al. 2013; Thiede et al. 2013; Xiao et al. 2012; Zhang et al. 2013) as well as in metabolomics research (Chen et al. 2012; Kamthan et al. 2012; Sun et al. 2012; Zhang et al. 2012). Moreover, contemporary $2 \mathrm{DE}$ instruments' ability to run dozens of 2DE experiments in parallel offers improved reliability and reproducibility (Rabilloud et al. 2010).

Keywords. Paper wick; sample preparation; sonication; streaking; two-dimensional electrophoresis

Abbreviations used: ARS, acidic region streaking; dd-Milli-Q, double distilled Milli-Q water; MC-tube, microcentrifuge tube; NuA, nucleic acid; RB, rehydration buffer; WCPE, whole cell protein extract

Supplementary materials pertaining to this article are available on the Journal of Biosciences Website at http://www.ias.ac.in/jbiosci/ sep2014/supp/Roy.pdf 
Ideally proteins should appear on a 2DE gel as localized concentric spots. However, artifacts are common problems in 2DE. One such very common artifact is streaking (Cremer and Van de Walle 1985; Hatairaktham et al. 2013; Havanapan and Thongboonkerd 2009; Jiang et al. 2011; O'Farrell 1975; Qi et al. 2013). A streaking on a 2DE gel may be defined as a horizontal or a vertical stretch of stained region with intensity greater than the local background and can conceal a spot. Streaking poses great obstacles during image analysis and confers ambiguity during protein identification. The problem of horizontal streaking at basic region and vertical streaking is more or less answered (Bai et al. 2005; Görg et al. 1987,1997, 2000; Havanapan and Thongboonkerd 2009; O'Farrell 1975; Olsson et al. 2002; Pennington et al. 2004). But streaking at the acidic end as such is relatively unattended (Antonioli et al. 2009; Herbert et al. 2006), where there is scope for major improvement. Acidic region streaking (ARS) generally starts from about $\mathrm{pH} 5$ extending towards lower $\mathrm{pH}$ region smearing especially for high molecular weight proteins. Given that a large number of proteins (more than $17 \%$ of the E. coli proteins) have pI below pH 5, ARS may obscure lot of important information. On overview of dramatically varying quality of $2 \mathrm{D}$ gels in terms of streaking and number of clear spots can be seen in archived gel images at EcoProDB(Yun et al. 2007).

Among the many factors that contribute to streaking, nucleic acid $(\mathrm{NuA})$ contamination is among the most frequent cause for ARS (Antonioli et al. 2009; Rabilloud 1996; Westermeier and Naven 2002). Although treatment with nucleases and/or selective protein precipitationresolubilization (cleanup) are suggested to eliminate $\mathrm{NuA}$ contamination (Antonioli et al. 2009; Rabilloud 1996), these are prone to errors due to attenuated nuclease activity in strong denaturing buffer, inadequate resolubilization of proteins, or risk of leftover contamination from enzymes and acids. Not surprisingly, ARS is commonly seen in contemporary 2DE gels, even with the simplest 2DE sample, such as the E. coli whole cell protein extract (WCPE) (Liao et al. 2011; Nakata et al. 2010; Qi et al. 2013; Ramachandran et al. 2012; Riley et al. 2012). Efforts have been made on improving protein recovery without eliminating streaking (Valente et al. 2012), which may result in loss of potentially important expression information. Furthermore, any additional step adds to the already multi-step protocol of 2DE, potentially affecting protein recovery and the protein profile itself (Rabilloud 1996). However, for some samples (e.g., plant or plasma samples), cleanup and/or multiple depletion cycles becomes essential in order to get any meaningful profile from 2DE gels (Damerval et al. 1986). On the other hand, E. coli and prokaryotic WCPE in general have low salt content, giving us an opportunity to simplify the sample preparation step with the aim to maximize protein recovery without disturbing the protein profile.
In this article, a simple solution for ARS is reproducibly demonstrated on E. coli and M. smegmatis 2DE gels, for which no exclusive sample cleanup was performed. The whole cell lysate was prepared by sonication of the cells in pure water (rather than in urea/thiourea buffer), under fixed temperature of an ice-water bath. A suitable buffer, IEF program, and a modified paper wick usage, yielded improved 2DE gels with negligible or no streaking. An indirect protein estimation appropriate for $2 \mathrm{DE}$ gel samples was used, as an alternative for costly 2DE-quantification kits. Our designed protocols are expected to provide 2DE gels without ARS, at less time and lower cost, with improved protein recovery and quantitative protein profile.

\section{Materials and methods}

WCPE samples from E. coli and Mycobacterium smegmatis were prepared using known protocols, and our modified protocol (figure 1; supplementary figure 1). Parameters of 2DE experiment were optimized iteratively. Final protocols were repeated at least thrice for reliability. We compared our results against few recently published $E$. coli and $M$. smegmatis WCPE 2DE gels.

\subsection{Chemicals and reagents}

Double distilled Milli-Q water (dd-Milli-Q) was used where high quality water was preferable. Urea, DTT, BSA, Tris, SDS, acrylamide, bis-acrylamide, EDTA, $\beta$ Marcaptoethanol, Tween-80, RNase and bromophenol blue were purchased from Sigma-Aldrich, St Louis, Mo, USA. Thiourea was purchased from S. D. Fine-Chem Limited, (Mumbai). CHAPS was purchased from G-Biosciences, St Louis, Mo, USA. IPG strips, mineral oil and Bio-Lyte 3/10 ampholyte were purchased from Bio-Rad, Hercules, CA, USA. Sample clean up kit was purchased from Amersham Biosciences Corp., Piscataway, USA and coomassie brilliant blue R-250 was purchased from Amresco Inc., Solon, Ohio. DNase was purchased from SRL Pvt. Ltd. (Maharashtra, India).

\subsection{Harvesting cells (supplementary figure 1, steps 1 to 4)}

E. coli $\mathrm{K}-12$, thi1, relA1, spoT1 (Low 1968) cells grown in Lysogeny broth $(10 \mathrm{~g} / \mathrm{L}$ tryptone, $5 \mathrm{~g} / \mathrm{L}$ yeast extract (Becton Dickinson India Pvt. Ltd., India) and $10 \mathrm{~g} / \mathrm{L} \mathrm{NaCl}$ ) media were collected by centrifugation at $6000 \mathrm{~g}$ for $10 \mathrm{~min}$. Cells were washed with ice-cold dd-Milli-Q thrice. Washed pellet was stored at $-20^{\circ} \mathrm{C}$ or processed immediately. Mycobacterium smegmatis cells were grown in Lysogeny broth with $0.2 \%$ Tween- 80 and harvested as mentioned above. 


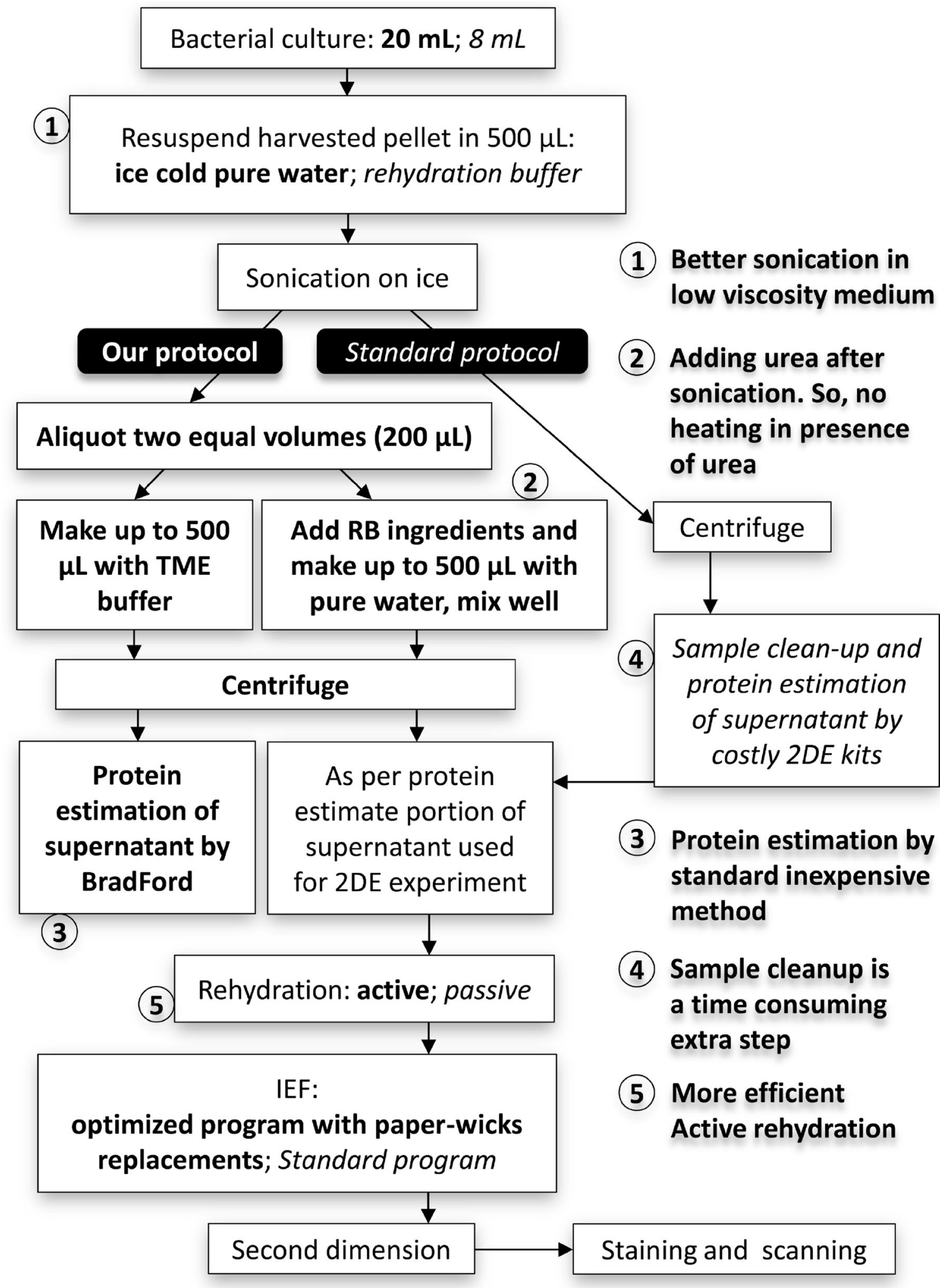

Figure 1. A flowchart showing the steps of standard protocol and our protocol for the complete 2DE experiment starting from bacterial cell culture to gel scanning. Following symbols indicate: $\square \rightarrow$ Steps in protocol; bold $\rightarrow$ steps unique to our protocol; italics $\rightarrow$ steps unique to standard protocol; annotations depicting pros and cons corresponding to specific steps in the protocol are numbered 1 to 5 . 
Two methods were employed to prepare the samples; our protocol (OP) and standard protocol (SP). Both are described below.

\subsection{Cell disruption (supplementary figure 1, step 5)}

OP: For E. coli WCPE, cell pellet from $20 \mathrm{~mL}$ culture was resuspended in total volume of $500 \mu \mathrm{L}$ ice-cold dd-Milli-Q water in a micro-centrifuge tube (MC-tube). Five rounds of sonication were performed with a micro-probe sonicator (Vibra-Cell, Sonics \& Materials Inc., Danbury, CT USA), keeping the MC-tube always inside ice. Each round was $40 \mathrm{~s}$ long consisting of $1 \mathrm{~s}$ on and $1 \mathrm{~s}$ off; 1 min cooling was allowed inside ice between two rounds. Intensity of sonication was carefully controlled to prevent frothing. For $M$. smegmatis WCPE, cell pellet from $40 \mathrm{~mL}$ culture equivalent was taken and the same procedure was followed as mentioned above, except that, due to its tough cell wall, 12 rounds of sonication were performed.

$S P$ : The rehydration buffer (RB) recipe was $7 \mathrm{M}$ urea, 2 M thiourea, 4\% CHAPS, $65 \mathrm{mM}$ DTT and 2\% ampholytes. E. coli cell pellet from $8 \mathrm{~mL}$ culture was resuspended in 500 $\mu \mathrm{L} \mathrm{RB}$ and sonication was done as above.

\subsection{Protein extraction (supplementary figure 1, steps 6 to 9)}

OP: $200 \mu \mathrm{L}$ lysed cell suspension was added to the solid constituents of RB $(210 \mu \mathrm{g}$ for $7 \mathrm{M}$ urea, $76 \mu \mathrm{g}$ for $2 \mathrm{M}$ thiourea and $20 \mu \mathrm{g}$ for $4 \%$ CHAPS) and mixed at room temperature. When no solid particles are visible, $16.25 \mu \mathrm{L}$ of $2 \mathrm{M}$ DTT solution and $10 \mu \mathrm{L}$ ampholyte was added. After complete dissolution volume was made up to $500 \mu \mathrm{L}$ with dd-Milli-Q water. After removing insoluble cell debris by spinning the suspension at $18,000 \mathrm{~g}$ for 15 minutes at $18^{\circ} \mathrm{C}$, the sample, '2DE extract' was stored at $-20^{\circ} \mathrm{C}$ in small aliquots $(100 \mu \mathrm{L})$ or immediately continued to next step. In a separate MC-tube $200 \mu \mathrm{L}$ of the lysed suspension was diluted to $500 \mu \mathrm{L}$ with ice cold TME buffer $(25 \mathrm{mM}$ Tris$\mathrm{HCl} \mathrm{pH} 8.0,2 \mathrm{mM} \beta$-Marcaptoethanol and $1 \mathrm{mM}$ $\mathrm{Na}_{2}$ EDTA). After spinning at $18,000 \mathrm{~g}$ for $15 \mathrm{~min}$ at $4^{\circ} \mathrm{C}$ supernatant was collected as 'TME extract'. In OP $500 \mu \mathrm{L}$ was taken for sonication, and then $200 \mu \mathrm{L}$ was added to buffer recipe. That means actually $2 / 5$ th of the $20 \mathrm{~mL}$ culture was added to buffer recipe. $2 / 5$ th of $20 \mathrm{~mL}$ is $(20 \times 2) / 5=8$ $\mathrm{mL}$.

$S P$ : Lysed cell suspension in RB was centrifuged $18,000 \mathrm{~g}$ for $15 \mathrm{~min}$ at $18^{\circ} \mathrm{C}$ and supernatant was collected as $2 \mathrm{DE}$ extract as mentioned above.

Sample cleanup: Extracted protein sample in RB was cleaned up using either clean up kit or using phenol/chloroform/isoamyl alcohol method. Cleanup kit was used exactly as mentioned in the instruction manual (Amersham-Biosciences 2003). Briefly, protein was precipitated with the addition of precipitant and co-precipitant. After centrifugation supernatant was discarded. The pellet was washed first with co-precipitant and then with dd-Milli-Q and thereafter with chilled-wash buffer. The pellet was allowed to dry and was subsequently resuspended in RB. Cleanup with phenol/chloroform/isoamyl alcohol was performed as described in the literature (Antonioli et al. 2009). In short, the sample in alkaline buffer (50 mM Tris, $\mathrm{pH} 9.5$ ) was thoroughly mixed with two volumes of phenol/chloroform/isoamyl alcohol (25:24:1) solution and allowed to sit for 5 minutes. After centrifuging at $21,000 \mathrm{~g}$ at $4^{\circ} \mathrm{C}$ for $10 \mathrm{~min}$ the upper aqueous layer and the bottom organic layer were carefully removed. Excess of acetone was added to wash the protein precipitate. After centrifugation, the pellet was either solubilized in rehydration buffer or proceeded to second round of phenol/ chloroform/isoamyl alcohol treatment.

Enzyme digestion: DNase/RNase was added to the sonicated suspension prior to centrifugation. The enzyme solutions contained required amount of ions $\mathrm{MgCl}_{2}$ for their activity. The mixtures were incubated on ice for 30 minutes (O'Farrell 1975).

\subsection{Protein estimation in $2 D E$ extract}

Given that RB components interfere with common colorimetric protein essays (Kao et al. 2008), we use a parallel approach wherein we estimate the protein quantity in TME extract using the Bradford assay (Bradford 1976) with the help of a spectrophotometer (Genesys 10UV, Thermo Scientific). Standard curve was prepared with a $100 \mu \mathrm{g} / \mathrm{mL}$ solution of BSA in dd-Milli-Q. Since both the samples, namely 2DE extract and TME extract, had the same amount of lysed cell suspension and was made up to the same volume (section 2.4), they are expected to contain the equivalent amount of protein, assuming homogeneity and neglecting pipetting, instrument error. SDS-PAGE with equal volume load from both samples confirmed (supplementary figure 2 , lanes 1 and 2 , and supplementary figure 3 ) the similar amount of protein content in TME extract and 2DE extract. This parallel method can be safely leveraged to suitably estimate the protein content before running $2 \mathrm{DE}$ gels as an alternative to the complicated and costly use of 2DE protein estimation kits.

\subsection{Rehydration}

$O P$ : To run 2DE with $7 \mathrm{~cm}$ IPG strip $50 \mu \mathrm{g}(200 \mu \mathrm{g}$ for 17 $\mathrm{cm}$ ) of $2 \mathrm{DE}$ extract (E. coli or M. smegmatis) was diluted to $125 \mu \mathrm{L}(300 \mu \mathrm{L}$ for $17 \mathrm{~cm})$ with $\mathrm{RB}$ and a trace of Bromophenol Blue, mixed thoroughly and kept at $20^{\circ} \mathrm{C}$ for 
half an hour. This mixture was then centrifuged at $18,000 \mathrm{~g}$ at $20^{\circ} \mathrm{C}$ for $15 \mathrm{~min}$ to remove any insoluble particles. PROTEAN IEF focusing tray (Bio-Rad) was cleaned with dilute SDS solution, gently brushing with a soft nylon brush. The tray was rinsed and brushed under streaming de-ionized water to remove SDS. This process was repeated till no trace of mineral oil was left. Finally the tray was thoroughly rinsed with Milli-Q water and kept for drying inside an airflow hood. The dry tray was placed inside a PROTEAN IEF cell (Bio-Rad). The IPG strip was rehydrated under active rehydration mode ( $50 \mathrm{~V}$ constant) for $12 \mathrm{~h}$ as instructed by the instrument manual (Bio-Rad 2011).

$S P$ : IPG strips were rehydrated as above, but in passive mode, without applying any voltage.

\subsection{Isoelectric focusing}

After rehydration, the oil on the strip was soaked off with a moistened filter paper (supplementary figure 4, steps 2-4). Two paper wicks, cut from WHATMAN filter paper No. 3, were placed on the electrodes of a fresh clean lane of the IEF tray and $10-15 \mu \mathrm{L}$ dd-Milli-Q was added to the wicks (supplementary figure 4, step 5). Excess water was blotted off with a filter paper (supplementary figure 4 , step 6). Thereafter, the strip was placed in the lane, gel-side down on the moistened paper wicks (supplementary figure 4, step 7). IEF was performed with standardized program depicted in supplementary figure 5 . The maximum allowed current was set to $50 \mu \mathrm{A}$. Paper wicks were changed (supplementary figure 4, steps 4-7) every hour for at least two (for $7 \mathrm{~cm}$ ) to three (for $17 \mathrm{~cm}$ ) times after the start of IEF. After this, paper wick changing was continued until the current dropped below $10 \mu \mathrm{A}$ per gel. Otherwise, the wicks were changed until the final voltage was reached or maximum twice, whichever was earlier.

\subsection{Second dimension}

Strip was equilibrated in the equilibration buffer I and II (Bio-Rad 2011) for 15 minutes each at room temperature. After this, the strip was rinsed in SDS-running buffer and loaded on the surface of an SDS-PAGE gel. Melted overlay agarose was laid on the strip. SDS-PAGE was run at constant current at $200 \mathrm{~V}$ (for $17 \mathrm{~cm}$, at $10 \mathrm{~mA}$ for $30 \mathrm{~min}$ and then at $16 \mathrm{~mA}$ ) till the dye front reached the lower bottom of the gel.

\subsection{Staining and scanning of gels}

Staining was done with coomassie brilliant blue R250 and destaining with $10 \%$ acetic acid and $10 \%$ methanol solution. Gels were scanned in a Bio-Rad 2DE gel scanner and saved in '.mel' format.

\subsection{Agarose gel electrophoresis}

Samples were run on $1 \%$ agarose (with a pinch of Ethidium bromide) horizontal gels to check for nucleic acid contamination. Gels were run at constant voltage of 90 volts. After the run, gels were scanned inside an UV illuminated scanner.

\subsection{Measurement of ARS}

Approximate length of horizontal streaks in the acidic region was measured using Gimp image editing software, from published 2DE gel images available in 'portable document format (PDF)'. We analyzed 2DE gel images, including those from $E$. coli WCPE published in the last one year, emphasizing papers optimizing 2DE gels from E. coli WCPE. We analyzed all published 2DE gel images of M. smegmatis WCPE accessible to us. ARS was defined as a horizontal stretch of stained line visible on the gel with intensity more than the local background intensity. The distance between two $\mathrm{pH}$ ends of a streak was measured in pixel units $(\mathrm{x})$. The length of the longest streak was assigned as (y) pixel units. Therefore, from the $\mathrm{pH}$ range information (e.g., if the IEF $\mathrm{pH}$ range was 4-7 then $\mathrm{a}=4$ and $\mathrm{b}=7$ ) an approximate streak-length was calculated in terms of $\mathrm{pH}$ units using the equation: Length of streaking $=\frac{x}{y} \times(b-a)$. Number of ARS visible was also recorded; a number 10 meant that the gel had $\geq 10$ ARS. 2DE gel images were analyzed with 'ImageMaster 2D Platinum 7.0' software; number of spots detected was recorded for comparison.

\section{Results}

\subsection{Effect of ampholyte concentration}

For $E$. coli WCPE many variations of buffer recipe have been previously used; however, the standard RB (7 M urea, $2 \mathrm{M}$ thiourea, $65 \mathrm{mM}$ DTT and 4\% CHAPS) gave us better results, compared to other compositions (supplementary figure 6). We have checked with ampholyte ( $\mathrm{pH} \mathrm{3-10)}$ concentrations of $0.5 \%$ (figure $2 \mathrm{Ai}$ ), $1 \%$ (data is not shown) and $2 \%$ (figure 2Aii). Low ampholyte concentration (0.5\%) produced poorly focused gels with horizontal streaking throughout the gel. Increased concentration of ampholyte (2\%) showed better focusing and streaking was limited to the acidic region.

\subsection{Elimination of $\mathrm{NuA}$ contamination}

To systematically address the problem of ARS (figure 2Aii) we revisited the issue of non-protein impurity reduction in 
WCPE. Standard sample cleanup was performed, which improved focusing, but ARS was visible even with low protein load (supplementary figure 7). It may be noted that relatively high amounts of NuA contamination in E. coli WCPE is known to cause ARS (Antonioli et al. 2009; Rabilloud 1996; Westermeier and Naven 2002); however, amount of salt, due to its low molar content, is not an issue. Interestingly, digestion with nuclease in $\mathrm{RB}$ medium could not completely remove the genomic DNA (compare figure $2 \mathrm{~B}$, lanes 2 and 3); neither did it affect the protein recovery much (compare supplementary figure 2 , lanes 4 and 5). After cleanup with phenol/chloroform/isoamyl alcohol (Antonioli et al. 2009), a substantial amount of $\mathrm{NuA}$ was removed (figure 2B, lanes 4 and 5); however, repeated precipitation and resolubilization of WCPE incurred a significant amount of protein loss (compare supplementary figure 2 , lanes 4 and 6 ).

To alleviate the denaturing effect of RB on the activity of nucleases we attempted digestion of $\mathrm{NuA}$ in plain water (TME or other buffers were avoided to reduce salt contamination). For that we sonicated cells in water and then added enzymes and the required ingredients. As a result an efficient removal of small-to-medium $\mathrm{NuA}$, as well as the large genomic DNA was observed (figure 2B, lane 6).

In our protocol, we endeavored to prepare the sample without nuclease treatment, which entailed prolonged yet careful sonication in water. Sonication is known to shear large NuA molecules (Westermeier and Naven 2002), while sonication in a denser medium such as RB could not remove $\mathrm{NuA}$. Even increasing number of rounds of sonication in RB did not bring any apparent change in the result, and the large NuA contaminations were still conspicuous in agarose gel (data not shown). Controlled sonication in ice cold water in ice-water-bath followed by addition of RB ingredients and centrifugation resulted in almost similar result as with nuclease treatment (figure 2B, lane 7). Most importantly, the IEFinterfering large genomic DNA was not visible in the agarose gel. Moreover, the protein recovery was maintained similar compared to samples made by standard protocols (compare supplementary figure 2, lanes 1,2 and 3, and supplementary figure 3 ).

\subsection{IEF optimization and paper-wick changing strategy}

We adopted a prolonged IEF program (supplementary figure 5), lengthening the low-voltage initial steps to remove the contaminant ions, as well as the high-voltage final focusing step to compensate for the higher ampholyte concentration (Khoudoli et al. 2004). During IEF we replaced the paper wicks that accumulate contaminating ions. Wicks made from WHATMAN filter paper No. 3 improved our results compared to thin paper wicks. Importantly, the excess amount of water on the paper wick when not blotted away as mentioned above, gives rise to local clusters of horizontal streaks (supplementary figure 8B). Following our sample preparation, we reached the low current (below $10 \mu \mathrm{A}$ ) very soon, namely, after $2 \mathrm{~h}$ for $7 \mathrm{~cm}$ strips, and between 3 to 3.5 $\mathrm{h}$ for $17 \mathrm{~cm}$ strips. So, further changing of paper wicks was not necessary. The procedure gave us clean $2 \mathrm{DE}$ gel with more spots with negligible or no ARS (figure $2 \mathrm{Ci}$ and supplementary figure $8 \mathrm{~A}$ ). For samples treated with nuclease, some background streaking could be observed in the acidic parts of the gels and spots had smearing at both ends. When nuclease treatment was excluded, gels were highly improved with more focused spots and negligible or no ARS (figure 2Cii) even in the low $\mathrm{pH}$ range (figure 2Di). The method is reproducible and assures good protein recovery.

\subsection{Test of robustness of the method}

To establish the effectiveness of our procedure to eliminate ARS for WCPE from a variety of bacteria, we applied the procedure to E. coli and M. smegmatis. E. coli is from phylum proteobacteria, while $M$. smegmatis is from actinobacteria. Most importantly, $M$. smegmatis has a hydrophobic cell wall enriched with mycolic acid content. The proteome consists of over 6000 proteins, about 2400 more than that of E. coli. Consequently, there are higher number of proteins in the $\mathrm{pH} 4-7$ range; especially clustered around $\mathrm{pH}$ 5 (supplementary figure 9A and B). M. smegmatis also expresses a higher percentage of hydrophobic proteins than E. coli (supplementary figure $9 \mathrm{C}$ and D). In spite of the distinct profile of WCPE from the two organisms, our method produced clean 2DE gels, especially for M. smegmatis WCPE with large number of spots with negligible or no ARS (figure 2Dii).

\subsection{Comparative analysis of ARS}

We present a measurement of streaking in terms of approximate $\mathrm{pH}$ units as described in section 2.11. We calculated the length of the longest ARS and number of such ARS in gels produced by our protocol (OP) and gels published in few recent articles (figure 3, supplementary figure 10, supplementary tables 1 and 2). It was found that our method produced shortest and lowest number of ARS, if at all. We also compared the number of spots detected in our 2DE gels with the ones which specifically dealt with ARS in 2DE with E. coli WCPE.

The work of Antonioli et al. discussing elimination of DNA/RNA contamination in E. coli WCPE (Antonioli et al. 2009), detected an average of 770 spots with Sypro Ruby staining in the $\mathrm{pH}$ range 3-10. We were able to detect 666 spots from E. coli WCPE on a smaller $\mathrm{pH}$ range of $\mathrm{pH} 4-7$ with coomassie R250 staining. It may be noted that Sypro 

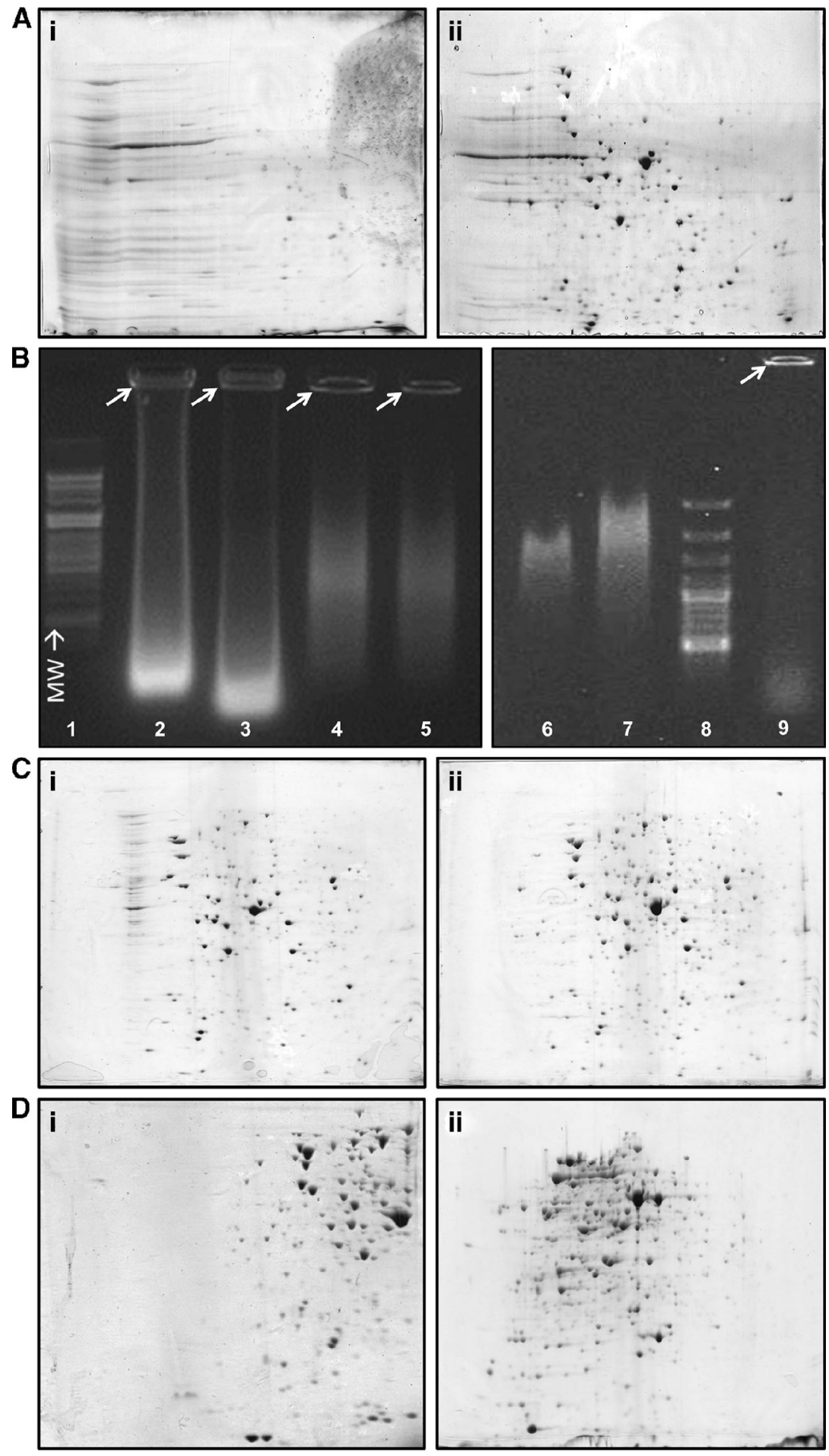

Figure 2. (A) $2 \mathrm{DE}$ images of $E$. coli $\mathrm{WCPE}$ on $\mathrm{pH} 4-7 \mathrm{IPG} 17 \mathrm{~cm}$ strips: (i) With $0.5 \%$ ampholytes and (ii) with $2 \%$ ampholytes. (B) Agarose gel electrophoresis images of E. coli WCPE. Lane marked (2) correspond to SP, (3) SP followed by DNase/RNase treatment, (4) SP followed by one round of Phenol/chloroform/isoamyl alcohol treatment, (5) SP followed by two rounds of Phenol/chloroform/isoamyl alcohol treatment, (6) OP followed by DNase/RNase treatment, (7) OP alone, (9) SP followed by clean up. Lanes marked 1 and 8 show molecular weight markers. The white band highlighted using an arrow indicates genomic DNA. (C) 2DE images of $E$. coli WCPE on pH 47 IPG $17 \mathrm{~cm}$ strips: (i) made by OP then DNase/RNase treated and (ii) made by OP with optimized IEF. (D) 2DE image of (i) E. coli WCPE on pH3-6 IPG $17 \mathrm{~cm}$ strip produced with OP and (ii) M. smegmatis WCPE on pH4-7 IPG $17 \mathrm{~cm}$ strip produced with our optimized protocol. 
Ruby is known to detect twice more spots than coomassie R250 (Chiangjong and Thongboonkerd 2009). In another 2DE optimization work with E. coli WCPE, Valente et al. detected 626 spots in $\mathrm{pH} 3-10$ with marginal streaking (Valente et al. 2012). In case of M. smegmatis WCPE, OP yielded 780 2DE spots in $\mathrm{pH} 4-7$ compared to 231 in $\mathrm{pH} 3-$ 10 (Shires and Steyn 2001) from published 2DE images with no ARS. It may be noted that there are several resources, for example, EcoProDB (Yun et al. 2007), that provide comprehensive information on $2 \mathrm{D}$ gels and associated proteome, but none have surveyed the streaking present in the archived gels and presented a comparative assessment of quality based on the same.

\section{Discussion}

\subsection{An optimum buffer recipe}

One of the major factor in trouble-shooting streaking is protein solubility (Görg et al. 2000). Proteins need to be solubilized effectively throughout the duration of IEF run. An effective solubilizing buffer also increases the number of different proteins analysable in a 2D gel. A variety of 2DEbuffer recipes have been used by researchers over the years. Urea, thiourea, CHAPS and DTT concentrations have already been standardized for E. coli; several manipulations have been attempted which did not necessarily result in good 2DE gels (Choe and Lee 2000; Han et al. 2005; Herbert et al. 2006; Nandakumar et al. 2003; Smejkal et al. 2006; Valente et al. 2012). We suggest a suitable $2 \mathrm{DE}-$ buffer recipe, i.e. 7 $\mathrm{M}$ urea, $2 \mathrm{M}$ thiourea, $65 \mathrm{mM}$ DTT, 4\% CHAPS and 2\% ampholytes. Ampholytes help in solubilization of proteins near their $\mathrm{pI}$ (Righetti et al. 2007; Westermeier and Naven 2002), aids in removing nucleic acids (Rabilloud 1996; Rabilloud et al. 1986; Shaw and Riederer 2003) and also scavenges cyanate ions responsible for non-specific modification of proteins (Shaw and Riederer 2003). Generally $0.5 \%$ to $2 \%$ of ampholyte is recommended (Shaw and Riederer 2003); according to our observations $2 \%$ of ampholytes is optimum. We have used molecular biologygrade urea, ordinary-grade thiourea, electrophoresis-grade CHAPS and DTT and dd-Milli-Q. Ultrapure reagents will produce even better quality $2 \mathrm{DE}$ gels.

\subsection{Removal of NuA contamination and simplified protein extraction}

Apart from causing ARS, the large NuA molecules become too viscous to work with, in RB. There are two main strategies generally practiced to remove NuA contamination. One is digestion by nuclease and the other is selective precipitation of proteins from contaminating medium and resolubilization in RB. These are often practiced separately or in tandem in sample preparation of 2DE (Görg 2004; Stasyk et al. 2001). The cleanup procedure removes contaminants like salts, NuA and polysaccharides. A strategy involving precipitating proteins in the aqueous-organic interface (Antonioli et al. 2009) has been shown to be effective in removing NuA. However, precipitation and resolubilization steps in the cleanup process do not ensure total recovery of proteins. Very often significant amounts of proteins are disproportionately lost during cleanup process especially when multiple rounds of processing is needed, which

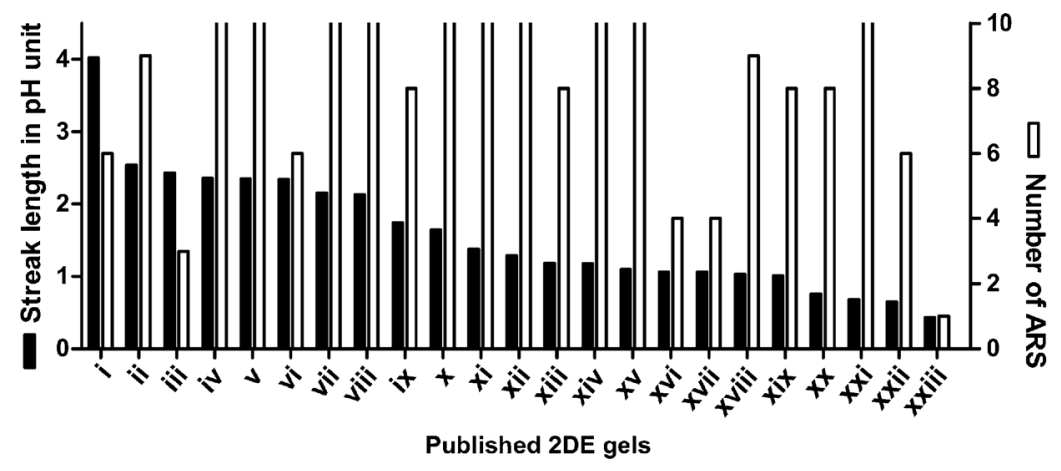

Figure 3. Histogram of length of streaking and number of ARS in few recently published literature, including those discussing 2DE optimization with E. coli WCPE. The open bars represent cases with at least 10 ARS. The Roman numerals at the x-axis represent the following publications: (i) (Fedyunin et al. 2012); (ii) (Zuo and Speicher 2000); (iii) (Valente et al. 2012) (Fig. 5E); (iv) (Nandakumar et al. 2003); (v) (Cheung et al. 2012); (vi) (Choe and Lee 2000); (vii) (Valente et al. 2012) (Fig. 5D); (viii) (Qi et al. 2013) (Fig. 1B); (ix) (Kim et al. 2012) (Fig. 5A); (x) (Kim et al. 2012) (Fig. 5B); (xi) (Smejkal et al. 2006); (xii) (Herbert et al. 2006); (xiii) (Qi et al. 2013) (Fig. 1A); (xiv) (Han et al. 2005); (xv) (Riley et al. 2012) (Fig. 2C); (xvi) (Ramachandran et al. 2012); (xvii) (Piras et al. 2012); (xviii) (Aich et al. 2012); (xix) (Ramachandran et al. 2012) (Fig. 5C); (xx) (Schliep et al. 2012); (xxi) (Riley et al. 2012) (Fig. 2A); (xxii) (Aich et al. 2012); (xxiii) This work. Figure numbers were mentioned where more than one 2DE gel image was used. 
limits the use of 2DE in quantitative applications. Also, in some cases the acid used for sample precipitation carries over to final 2DE solution producing artifacts. Difficulty in solubilizing the protein precipitate is also a commonly faced problem. Because of the low salt content of $E$. coli, WCPE sample cleanup may be avoided if $\mathrm{NuA}$ is eliminated by any other means. A moderate amount of salt contamination may also be addressed by our IEF program and paper wick strategy.

In our study, the cleanup procedure did not achieve efficient removal of $\mathrm{NuA}$, suggesting necessity of multiple rounds of processing. It is likely that we did not get enough nuclease activity in strongly denaturing RB. Besides such an approach adds extra contamination in the form of foreign proteins, salts and other substances (needed for enzyme activity and stability) preventing from producing well focused spots.

We demonstrated that sonication of cells in dd-Milli-Q maintaining ice-cold environment rather than sonicating in RB yields better results. While sonication is a standard technique regularly used in sample preparation, effective sonication is significantly improved by lowering the viscosity of the aqueous medium by using pure water instead of RB, allowing better transmission of ultrasound wave. More rounds of sonication in RB or use of maximum allowed power could not compensate for the advantage associated with low viscosity of water. Presence of detergent in RB causes frothing, which is easily avoided in pure water. Therefore, sonication in less viscous water not only facilitates cell rupture but total shearing of DNA molecules as well. The small amount of low-to-medium sized NuA molecules still present did not pose any serious problem when we optimized other parameters in 2DE protocol. It is pertinent to ask if sonication could collaterally lead to breaking of protein backbones, especially of the large ones. It has been previously shown that such breakage, if at all, is minor and becomes insignificant at higher protein concentrations as it imparts a protective effect against mechanical shear (Coakley et al. 1973). This is also corroborated by the supplementary figure 2, lane 2 and 3, depicting gel electrophoresis pattern by our protocol and standard protocol, which show no obvious differences. Furthermore, the sonication step requires at the most $10 \mathrm{~min}$, and considering the benefits of clear 2DE gels anticipated, the protocol offers clear advantage compared to minor increase of work load or time of sample preparation.

The advantages of our protocol are manifold. Foremost of these is the simplified sample preparation protocol involving minimal steps. Simpler procedure means lesser manual error, yielding improved reproducibility both in terms of recoveries and maintenance of stoichiometric amounts of the proteins important for accurate quantitative proteome analyses. It minimizes transfer of proteins from one solution to the other, which helps maintain original protein composition. Our protocol effectively removes IEF-interfering $\mathrm{NuA}$, avoiding any further processing or enzymatic treatment. This eliminates the chance of external contaminants coming into the sample. We also did not need to expose the proteins for long-time incubation at room temperature, needed for nuclease digestion. Finally, because the procedure is short, it ensures protein stability without the need for addition of protease inhibitors, ensuring minimum modification of the WCPE as well.

\subsection{Optimized IEF and paper wick replacement strategy}

In recent years, short IEF programs are being supported for their fast processing time. However, in our experience, a $12 \mathrm{~h}$ active rehydration and considerably long IEF program gives improved results. Active rehydration with $50 \mathrm{~V}$ constant voltage applied between electrodes ensures better absorption of sample in to the IPG strip gel. The IEF program we state (supplementary figure 5) starts with low voltage of 250 to $300 \mathrm{~V}$ for few hours, so as to carry the salt and other conducting small molecules into the paper wicks at the ends. As the paper wicks are changed on hourly basis, more and more conducting substances are removed from the IEF system and the current drops. Slowly we increase the voltage step by step and finally, after a considerable salt removal period, we move towards higher voltage (3500 to 8000 $\mathrm{V})$ when protein molecules can be mobilized towards their focal point in the $\mathrm{pH}$ gradient on the IPG strip. The program was run till required volt-hours were achieved (dotted lines in supplementary figure 5).

The idea of changing paper wicks was highlighted more than a decade back in 1997 by Görg et al. (1997), who observed that changing cathodic paper wick during IEF help to reduce dryness of the gel at the cathodic side of the IPG strip. Lai et al. (2003) in 2003 noticed an improvement in focusing when paper wicks were changed frequently together with longer IEF for Bacillus subtilis spore sample; but these reports did not provide any detailed information on the wick changing strategy. This may be a possible reason why its use is not as commonly reported in literature despite clear benefits associated to it. In this work we have given detailed criteria for changing paper wicks and showed that regular changing of the paper wicks alongside an optimized IEF program can improve the quality of $2 \mathrm{DE}$ gels both in terms of minimal streaking and more spots.

\subsection{A robust protocol}

M. smegmatis being an acid-fast Gram-positive bacterium has higher fatty acid content and a very different proteome profile and cell composition than E. coli. But our OP is quite robust in eliminating ARS when applied to WCPE from diverse organisms. It is noteworthy that a higher amount (twice that of $E$. coli) of initial cell pellet of $M$. smegmatis was required to reach similar final total protein concentrations. It may also be noted that we have demonstrated the use of our protocol in both 7 and $17 \mathrm{~cm}$ IPG strips wherein the 
IEF program and the paper-wick changing strategy could be scaled using a common principle, suggesting its utility for any length IPG strip.

\subsection{Comparative analysis of performance}

The comparative analysis showed that our method effectively eliminates ARS from 2DEs of two very different types of bacteria, E. coli and M. smegmatis. At the same time it improves the number of detected spots in those 2DEs. It may also be noted that there have been publications on 2DE optimization over the years, but there is not much correlation between the year of publication and the extent of streaking. This justifies the high relevance of this work in the field of proteomics.

The two goals of a 2DE protocol are to produce clean 2DE gels without any artifacts, like ARS, and to reveal the protein composition of the sample devoid of any loss or modification (Westermeier and Naven 2002). We showed that both of the goals can be achieved at the same time with our protocol, demonstrated with $E$. coli and M. smegmatis WCPE. Our protocol proposes a suitable 2DE-buffer recipe for WCPE, i.e. $7 \mathrm{M}$ urea, $2 \mathrm{M}$ thiourea, $4 \%$ CHAPS, $65 \mathrm{mM}$ DTT and $2 \%$ ampholytes. We have greatly simplified the sample preparation procedure by excluding the standard sample cleanup, while maintaining protein recovery and avoiding unnecessary contaminants. We present an optimized IEF program for wellresolved IEF of proteins eliminating ARS. Our methodology will simplify the procedure, thereby allowing cost-effective, time-efficient and improved-quality 2DE gels.

\section{Acknowledgements}

This work was supported by the Department of Biotechnology, New Delhi, India.

\section{References}

Aich P, Patra M, Chatterjee AK, Roy SS and Basu T 2012 Calcium chloride made E. coli competent for uptake of extraneous DNA through overproduction of OmpC protein. Protein J, 31 366-373

Amersham-Biosciences 2003 2-D Clean-pp kit (Amersham Biosciences)

Antonioli P, Bachi A, Fasoli E and Righetti PG 2009 Efficient removal of DNA from proteomic samples prior to twodimensional map analysis. J. Chromatogr. A 1216 3606-3612

Bai F, Liu S and Witzmann FA 2005 A 'de-streaking' method for two-dimensional electrophoresis using the reducing agent tris(2carboxyethyl)-phosphine hydrochloride and alkylating agent vinylpyridine. Proteomics 5 2043-2047

Bio-Rad 2011 ReadyStrip IPG Strip. Instruction Manual
Bradford MM 1976 A rapid and sensitive method for the quantitation of microgram quantities of protein utilizing the principle of protein-dye binding. Anal. Biochem. 72 248-254

Butt AQ, Ahmed S, Maratha A and Miggin SM 2012 14-3-3epsilon and 14-3-3sigma inhibit Toll-like receptor (TLR)-mediated proinflammatory cytokine induction. J. Biol. Chem. 287 38665-38679

Chen YZ, Pang QY, He Y, Zhu N, Branstrom I, Yan XF and Chen S 2012 Proteomics and metabolomics of Arabidopsis responses to perturbation of glucosinolate biosynthesis. Mol. Plant 5 1138-1150

Cheung HY, Wong MM, Cheung SH, Liang LY, Lam YW and Chiu SK 2012 Differential actions of chlorhexidine on the cell wall of Bacillus subtilis and Escherichia coli. PLoS One 7 e36659

Chiangjong W and Thongboonkerd V 2009 A comparative study of different dyes for the detection of proteomes derived from Escherichia coli and MDCK cells: sensitivity and selectivity. $J$. Chromatogr. B. Anal. Technol. Biomed. Life Sci. 877 1433-1439

Choe LH and Lee KH 2000 A comparison of three commercially available isoelectric focusing units for proteome analysis: the multiphor, the IPGphor and the protean IEF cell. Electrophoresis 21 993-1000

Coakley WT, Brown RC, James CJ and Gould RK 1973 The inactivation of enzymes by ultrasonic cavitation at $20 \mathrm{kHz}$. Archives Biochem. Biophys. 159 722-729

Cremer F and Van de Walle C 1985 Method for extraction of proteins from green plant tissues for two-dimensional polyacrylamide gel electrophoresis. Anal. Biochem. 147 22-26

Damerval C, De Vienne D, Zivy M and Thiellement H 1986 Technical improvements in two-dimensional electrophoresis increase the level of genetic variation detected in wheat-seedling proteins. Electrophoresis 7 52-54

Fedyunin I, Lehnhardt L, Bohmer N, Kaufmann P, Zhang G and Ignatova Z 2012 tRNA concentration fine tunes protein solubility. FEBS Lett $\mathbf{5 8 6} 3336-3340$

Görg A 2004 2-D Electrophoresis principles and methods. $G E$ Healthcare 25-29

Görg A, Obermaier C, Boguth G, Csordas A, Diaz JJ and Madjar JJ 1997 Very alkaline immobilized pH gradients for twodimensional electrophoresis of ribosomal and nuclear proteins. Electrophoresis 18 328-337

Görg A, Obermaier C, Boguth G, Harder A, Scheibe B, Wildgruber R and Weiss W 2000 The current state of two-dimensional electrophoresis with immobilized $\mathrm{pH}$ gradients. Electrophoresis 21 1037-1053

Görg A, Postel W, Weser J, Günther S, Strahler JR, Hanash SM and Somerlot L 1987 Elimination of point streaking on silver stained two-dimensional gels by addition of iodoacetamide to the equilibration buffer. Electrophoresis 8 122-124

Han MJ, Lee JW and Lee SY 2005 Enhanced proteome profiling by inhibiting proteolysis with small heat shock proteins. J. Proteome Res. 4 2429-2434

Hatairaktham S, Srisawat C, Siritanaratkul N, Chiangjong W, Fucharoen S, Thongboonkerd V and Kalpravidh RW 2013 Differential plasma proteome profiles of mild versus severe beta-thalassemia/Hb E. Ann. Hematol. 92 365-377

Havanapan PO and Thongboonkerd V 2009 Are protease inhibitors required for gel-based proteomics of kidney and urine? J. Proteome. Res. 8 3109-3117 
Henzel WJ, Billeci TM, Stults JT, Wong SC, Grimley C and Watanabe C 1993 Identifying proteins from two-dimensional gels by molecular mass searching of peptide fragments in protein sequence databases. Proc. Natl. Acad. Sci. USA 90 5011-5015

Herbert BR, Grinyer J, McCarthy JT, Isaacs M, Harry EJ, Nevalainen H, Traini MD, Hunt S et al. 2006 Improved 2-DE of microorganisms after acidic extraction. Electrophoresis 27 1630-1640

Hong Y, Sun A, Zhang M, Gao F, Han Y, Fu Z, Shi Y and Lin J 2013 Proteomics analysis of differentially expressed proteins in schistosomula and adult worms of Schistosoma japonicum. Acta Trop. 126 1-10

James P, Quadroni M, Carafoli E and Gonnet G 1993 Protein identification by mass profile fingerprinting. Biochem. Biophys. Res. Commun. 195 58-64

Jiang T, Zhan Y, Sun M, Liu S, Zang S, Ma Y and Xin Y 2011 The novel responses of ethambutol against Mycobacterium smegmatis mc(2)155 revealed by proteomics analysis. Curr. Microbiol. 62 341-345

Kamthan M, Mukhopadhyay G, Chakraborty N, Chakraborty S and Datta A 2012 Quantitative proteomics and metabolomics approaches to demonstrate $\mathrm{N}$-acetyl-D-glucosamine inducible amino acid deprivation response as morphological switch in Candida albicans. Fungal Genet. Biol. 49 369-378

Kao S-H, Wong H-K, Chiang C-Y and Chen H-M 2008 Evaluating the compatibility of three colorimetric protein assays for twodimensional electrophoresis experiments. Proteomics 8 2178-2184

Khoudoli G, Porter I, Blow J and Swedlow J 2004 Optimisation of the two-dimensional gel electrophoresis protocol using the Taguchi approach. Proteome Sci. 26

Kim Y, Lee JW, Kang SG, Oh S and Griffiths MW 2012 Bifidobacterium spp. influences the production of autoinducer2 and biofilm formation by Escherichia coli $\mathrm{O} 157: \mathrm{H} 7$. Anaerobe 18 539-545

Lai EM, Phadke ND, Kachman MT, Giorno R, Vazquez S, Vazquez JA, Maddock JR and Driks A 2003 Proteomic analysis of the spore coats of Bacillus subtilis and Bacillus anthracis. J. Bacteriol. 185 1443-1454

Liao H, Zhang F, Hu X and Liao X 2011 Effects of high-pressure carbon dioxide on proteins and DNA in Escherichia coli. Microbiol. 157 709-720

Lopez JL 2007 Two-dimensional electrophoresis in proteome expression analysis. J. Chromatogr. B Analyt Technol. Biomed. Life Sci. 849 190-202

Low B 1968 Formation of merodiploids in matings with a class of Rec- recipient strains of Escherichia coli K12. Proc. Natl. Acad. Sci. USA 60 160-167

Nakata K, Koh MM, Tsuchido T and Matsumura Y 2010 All genomic mutations in the antimicrobial surfactant-resistant mutant, Escherichia coli OW66, are involved in cell resistance to surfactant. Appl. Microbiol. Biotechnol. 87 1895-1905

Nandakumar MP, Shen J, Raman B and Marten MR 2003 Solubilization of trichloroacetic acid (TCA) precipitated microbial proteins via naOH for two-dimensional electrophoresis. J. Proteome Res. 2 89-93

O'Farrell PH 1975 High resolution two-dimensional electrophoresis of proteins. J. Biol. Chem. 250 4007-4021
Olsson I, Larsson K, Palmgren R and Bjellqvist B 2002 Organic disulfides as a means to generate streak-free two-dimensional maps with narrow range basic immobilized $\mathrm{pH}$ gradient strips as first dimension. Proteomics 2 1630-1632

Pal P, Kanaujiya JK, Lochab S, Tripathi SB, Sanyal S, Behre G and Trivedi AK 2013 Proteomic analysis of rosiglitazone and guggulsterone treated 3T3-L1 preadipocytes. Mol. Cell Biochem. 376 81-93

Pappin DJ, Hojrup P and Bleasby AJ 1993 Rapid identification of proteins by peptide-mass fingerprinting. Curr. Biol. 3 327-332

Pennington K, McGregor E, Beasley CL, Everall I, Cotter D and Dunn MJ 2004 Optimization of the first dimension for separation by two-dimensional gel electrophoresis of basic proteins from human brain tissue. Proteomics 4 27-30

Piras C, Soggiu A, Bonizzi L, Gaviraghi A, Deriu F, De Martino L, Iovane G, Amoresano A 2012 Comparative proteomics to evaluate multi drug resistance in Escherichia coli. Mol. BioSyst. 8 1060-1067

Qi J, Du Y, Bai H, Zhu X, Hu M, Luo Y and Liu Y 2013 Global protein expression profile response of Escherichia coli ATCC 25922 exposed to enrofloxacin. Microb. Drug Resist 19 6-14

Rabilloud T 1996 Solubilization of proteins for electrophoretic analyses. Electrophoresis 17 813-829

Rabilloud T 2002 Two-dimensional gel electrophoresis in proteomics: old, old fashioned, but it still climbs up the mountains. Proteomics 2 3-10

Rabilloud T, Chevallet M, Luche S and Lelong C 2010 Twodimensional gel electrophoresis in proteomics: Past, present and future. J. Proteomics 73 2064-2077

Rabilloud T, Hubert M and Tarroux P 1986 Procedures for twodimensional electrophoretic analysis of nuclear proteins. $J$. Chromatogr. A 351 77-89

Rajani DK, Walch M, Martinvalet D, Thomas MP and Lieberman J 2012 Alterations in RNA processing during immune-mediated programmed cell death. Proc. Natl. Acad. Sci. USA 109 8688-8693

Ramachandran B, Dikshit KL and Dharmalingam K 2012 Recombinant $E$. coli expressing Vitreoscilla haemoglobin prefers aerobic metabolism under microaerobic conditions: a proteome-level study. J. Biosci. 37 617-633

Righetti PG, Simo C, Sebastiano R and Citterio A 2007 Carrier ampholytes for IEF, on their fortieth anniversary (1967-2007), brought to trial in court: the verdict. Electrophoresis 283799 3810

Riley LM, Veses-Garcia M, Hillman JD, Handfield M, McCarthy AJ and Allison HE 2012 Identification of genes expressed in cultures of E. coli lysogens carrying the Shiga toxin-encoding prophage Phi24B. BMC Microbiol 1242

Schliep M, Ryall B and Ferenci T 2012 The identification of global patterns and unique signatures of proteins across 14 environments using outer membrane proteomics of bacteria. Mol. Biosyst. 8 3017-3027

Shaw MM and Riederer BM 2003 Sample preparation for twodimensional gel electrophoresis. Proteomics 3 1408-1417

Shires K and Steyn L 2001 The cold-shock stress response in Mycobacterium smegmatis induces the expression of a histonelike protein. Mol. Microbiol. 39 994-1009 
Smejkal GB, Robinson MH, Lawrence NP, Tao F, Saravis CA and Schumacher RT 2006 Increased protein yields from Escherichia coli using pressure-cycling technology. J. Biomol. Tech. 17 173-175

Stasyk T, Hellman U and Souchelnytskyi S 2001 Optimizing sample preparation for 2-D electrophoresis. Life Sci. News 9 8-11

Sun H, Zhang A, Yan G, Han Y, Sun W, Ye Y and Wang X 2013 Proteomics study on the hepatoprotective effects of traditional Chinese medicine formulae Yin-Chen-Hao-Tang by a combination of two-dimensional polyacrylamide gel electrophoresis and matrix-assisted laser desorption/ionization-time of flight mass spectrometry. J. Pharm. Biomed. Anal. 75 173-179

Sun J, Li H and Yuan Q 2012 Metabolic regulation of trisporic acid on Blakeslea trispora revealed by a GC-MS-based metabolomic approach. PLoS One 7 e46110

Thiede B, Koehler CJ, Strozynski M, Treumann A, Stein R, Zimny-Arndt U, Schmid M and Jungblut PR 2013 High resolution quantitative proteomics of HeLa cells protein species using stable isotope labeling with amino acids in cell culture(SILAC), two-dimensional gel electrophoresis (2DE) and nano-liquid chromatograpohy coupled to an LTQOrbitrapMass spectrometer. Mol. Cell Proteomics 12 529-538

Valente KN, Choe L, Lenhoff A and Lee K 2012 Optimization of protein sample preparation for two-dimensional electrophoresis Electrophoresis 33 1947-1957
Westermeier R and Naven T 2002 Proteomics in practice (Weinheim: Wiley-VCH) p 19

Xiao H, Zhang L, Zhou H, Lee JM, Garon EB and Wong DT 2012 Proteomic analysis of human saliva from lung cancer patients using two-dimensional difference gel electrophoresis and mass spectrometry. Mol. Cell Proteomics 11 M111 012112

Yates JR 3rd, Speicher S, Griffin PR and Hunkapiller T 1993 Peptide mass maps: a highly informative approach to protein identification. Anal. Biochem. 214 397-408

Yun H, Lee JW, Jeong J, Chung J, Park JM, Myoung HN and Lee SY 2007 EcoProDB: the Escherichia coli protein database. Bioinformatics 23 2501-2503

Zhang B, Xu C, Zhang L, Zhou S, Feng S, He Y and Liao M 2013 Enhanced adherence to and invasion of PUVEC and PK-15 cells due to the overexpression of RfaD, ThyA and Mip in the DeltaompP2 mutant of Haemophilus parasuis SC096 strain. Vet. Microbiol. 162 713-723

Zhang Q, Lu YX and Xu WH 2012 Integrated proteomic and metabolomic analysis of larval brain associated with diapause induction and preparation in the cotton bollworm, Helicoverpa armigera. J. Proteome Res. 11 1042-1053

Zuo X and Speicher DW 2000 Quantitative evaluation of protein recoveries in two-dimensional electrophoresis with immobilized pH gradients. Electrophoresis 21 3035-3047

MS received 14 February 2014; accepted 31 May 2014

Corresponding editor: B JAGADEESHWAR RAO 